\title{
Estudo temporal das doenças associadas à AIDS no Brasil, 1980-1999
}

\author{
Temporal trends in AIDS-associated \\ opportunistic infections in Brazil, 1980-1999
}

\footnotetext{
1 Departamento de Medicina Preventiva e Social,

Faculdade de Medicina, Universidade Federal de Minas Gerais. Av. Alfredo Balena 190, 10 o andar, Belo Horizonte, MG, 30130-100, Brasil. drew@medicina.ufmg.br
}

Abstract Trends in annual incidence of reported AIDS-associated opportunistic infections (OI/100 adults $>12$ years old) among AIDS cases were estimated at the national level in Brazil from 1980 through May 1999. The analysis included chi-square and linear regression modeling. The opportunistic infections included: candidiasis (CD), tuberculosis (TB), Pneumocystis carinii pneumonia (PCP), neurotoxoplasmosis (NT), Kaposi sarcoma (KS), cryptococcal meningitis (CM), and protozoa infections (PI). The overall cumulative incidence rates/100 reported AIDS cases were: $C D=59$, $\mathrm{TB}=26, \mathrm{PCP}=23, \mathrm{NT}=15, \mathrm{KS}=5, \mathrm{CM}=4$, and $\mathrm{PI}=4$. Annual trends indicated a statistically significant decline in all Ols. However, in the Northeast and Central-West regions there were increases in TB $(b=0.39)$ and NT $(b=0.20)$, respectively. TB showed a higher incidence among individuals with less schooling (<8 years), while PCP and KS had higher incidence rates among those with 8 or more years of school ing, despitesimilar downward trends. Access to antiretroviral therapy and OI prophylaxis may partially explain these results. However, data reliability, delay in reporting, OI incidence after AIDS, and reporting and diagnostic criteria are factors that al so need to be carefully assessed. Key words Acquired Immunodeficiency Syndrome; Opportunistic Infections; Temporal Trend; Epidemiological Studies

Resumo Neste trabalho foram estimadas as incidências de condições associadas (CA) à AIDS/100 casos de AIDS em adultos (>12 anos), a nível nacional, de 1980 a mai o de 1999. A análise incluiu qui-quadrado e regressão linear simples. As CA anal isadas foram candi díase (CD), tuberculose (TB), pneumonia por Pneumocystis carinii (PCP), neurotoxoplasmose(NT), Herpes, Sarcoma de Kaposi (SK), meningi te criptocócica (MC) e infecções por protozoári os (IP). As incidênci as acumuladas/100 casos de AIDS foram: $C D=59, T B=26, P C P=23, N T=15$, Herpes $=12$, $\mathrm{SK}=5, \mathrm{MC}=4 \mathrm{eIP}=4$. A tendência anual indicou queda estatisticamente significativa em todas as CA. Entretando, houve aumento na incidência de TB $(b=0,39)$ e NT $(b=0,20)$, para as regiões Nordeste e Centro-Oeste, respectivamente. TB apresentou mai or inci dência entre aqueles com baixa escolaridade ( $<8$ anos), enquanto que PCP eSK tiveram maiores incidências entre aquel es com melhor escolaridade (8+anos), apesar de declínios semel hantes. Acesso à terapia anti-retroviral e profilaxi as para as CA explicam parcialmente estes resultados. Entretanto, a confiabilidade dos dados, o atraso na notifi cação, a incidência de CA pós-AIDS, bem como os critérios de notificação e diagnóstico, são fatores que devem ser avaliados.

Palavras-chave Síndrome da Imunodeficiência Adqui rida; Infecções Oportunistas; Tendência Temporal; Estudos Epidemiológicos 
Introdução

Estudos descritivos da propensão temporal da incidência de AIDS no Brasil indicam mudança em sua distribuição quanto a sexo, idade, região de residência, escolaridade e categorias de exposição. Tem sido apontada tendência de aumento da proporção de casos femininos, em direção a regiões mais distantes dos grandes centros urbanos, da categoria de exposição heterossexual e aumento de casos entre indivíduos com escolaridade igual ou menor a oito anos (10 grau e analfabetos). Estas inferências têm-se baseado nos casos de AIDS notificados ao Ministério da Saúde e em informações registradas na ficha de notificação, que é padronizada para o território nacional. A variável escolaridade tem sido utilizada como marcador de situação sócio-econômica, e o aumento na proporção de casos de AIDS naqueles com menor escolaridade tem sido denominado pauperização (CNDST/AIDS, 1999).

O surgimento de terapias mais eficazes inibidores de protease, terapia combinada para o tratamento de indivíduos infectados pelo vírus da imunodeficiência humana (HIV), além de profilaxias primárias e secundárias para infecções associadas à imunodeficiência, tem reduzido a mortalidade por AIDS de forma expressiva em diversos países, estando o Brasil entre estes (Mocroft et al., 1998; Palella et al., 1998; Chiasson et al., 1999; CNDST/ AIDS, 1999). No Brasil, esta diminuição ocorreu principalmente a partir de 1995-96, quando os medicamentos anti-retrovirais mais eficazes, incluindo inibidores de protease, começaram a ser disponibilizados na rede pública. Tem sido também demonstrada a diminuição na incidência das doenças associadas à AIDS - infecções oportunísticas - em vários países (Brodt et al., 1997; Palella et al., 1998; Jacobson et al., 1999). No entanto, não há estudos no Brasil que demonstrem se esta mesma tendência está ocorrendo, bem como se existiriam indícios de heterogeneidade quanto a sexo, região de residência, idade, categoria de exposição e escolaridade.

A presente análise objetivou avaliar a tendência temporal das doenças associadas à AIDS, a nível nacional, de acordo com variáveis sócio-demográficas selecionadas. Foi feita uma análise eminentemente descritiva, não havendo a proposta de, neste momento, realizar testes de hipóteses causais. Especial atenção foi dada à variável escolaridade - provável marcador de condição sócio-econômica - e, por isto, optou-se por excluir os casos de AIDS entre crianças menores de 13 anos de idade.

\section{Doenças associadas}

Foram estudadas as doenças associadas - indicadas no verso da ficha de notificação - como condições marcadoras de progressão clínica. Estas condições obedecem às revisões dos casos de AIDS do Ministério da Saúde e se baseiam principalmente em dois critérios clínicos: a) Definição do Rio de Janeiro (CNDST/AIDS, 1992) e b) Classificação do CDC - Centers for Disease Control and Prevention (CDC, 1992) modificada. Estes critérios clínicos fazem parte da definição de casos de AIDS em adultos para fins de notificação (CNDST/ AIDS, 1992, 1998a). Na primeira situação deve-se notificar todo caso que somar pelo menos dez pontos indicados na ficha, ao passo que, na segunda, o surgimento de qualquer uma das condições listadas. Os dados disponibilizados somente permitem analisar, a nível nacional, a ocorrência das doenças associadas quando da notificação - condições que indicam progressão clínica -, não sendo possível abordar a incidência destas condições subseqüente a esse momento.

Nesta análise optou-se por trabalhar com as oito principais condições associadas clinicamente mais específicas que estão registradas na ficha de notificação; algumas delas foram agrupadas visando facilitar a análise, sendo assim denominadas, neste texto, condi ções associadas. A Tabela 1 apresenta tais condições, os agrupamentos e as denominações utilizadas.

\section{Tendência}

As condições associadas foram analisadas de 1980 a maio de 1999, tendo-se agrupado os anos de 1980 a 1988 e os de 1998 e 1999 em virtude dos pequenos números. As diferenças de proporção foram avaliadas através do qui-quadrado, e as ten dências temporais, mediante regressão linear simples. Foram estimados os interceptos e as inclinações de cada curva (beta), os quais foram estimados para verificar se eram estatisticamente diferentes de zero ao nível de significância de 0,05.

Foi feita uma descrição global (1980-1999) dos casos notificados quanto ao sexo, a idade, as categorias de exposição, a região de residência, a escolaridade e as condições associadas. Para tanto, recorreu-se ao banco de dados fornecido pela Coordenação Nacional de DST e AIDS, que contém as informações dos casos de AIDS notificados até 29 de maio de 1999. As análises de tendência das condições associadas foram também efetuadas de forma global e estratificadas pelas variáveis independentes 
selecionadas. Como cada caso de AIDS notificado pode ter mais de uma condição associada, optou-se por tratar cada uma destas em separado. Para cada ano, estimou-se a proporção da condição associada, apresentando, como numerador, o número de casos de cada condição e, como denominador, o total de casos de AIDS notificados. De forma semel hante, estimou-se a proporção da cada condição associada para os subgrupos das variáveis selecionadas (e.g., para a categoria de escolaridade analfabetos, o numerador foi o número de casos de cada condição associada nesta categoria e, o denominador, o número de casos de AIDS também nesta categoria, em cada ano).

Essas proporções estimadas refletem, em tese, condições clínicas novas, marcadoras de progressão clínica, e casos incidentes, que ocorreram em cada ano. Dois fatores limitam a utilização mais rigorosa do termo incidência: a) ausência de datas que caracterizem quando as condições ocorreram; e b) falta de padronização do instrumento de notificação. Alguns casos são notificados de modo a indicar todas as condições ocorridas com aquele indivíduo até o momento da notificação, enquanto outros indicam apenas as condições marcadoras de progressão naquele momento. Apesar disto, optou-se por tratar esse indicador como incidência em relação ao universo de casos notificados em cada ano - por 100 casos de AIDS notificados -, uma vez que se procura captar a dinâmica temporal da ocorrência destas condições, reconhecendo as limitações inerentes ao tipo de dado disponível.

Finalmente, para a variável escolaridade, foi feita também sua distribuição anual entre aqueles com cada condição associada. Além disto, para cada condição associada, estimouse a razão das incidências (RI) para os períodos inicial (1980-1988) e final (1998-99), comparando-se os analfabetos e aqueles com 1o grau com a categoria 2 o grau ou mais.

\section{Variáveis independentes}

Foram estudadas as variáveis sexo, idade ( $<30$ e 30+anos), categoria de exposição (heterossexual, homo/bissexual, transmissão sangüínea, usuários de drogas injetáveis (UDI) e outros/ ignorados), região de residência (Centro-Oeste, Nordeste, Norte, Sudeste e Sul) e a escolaridade (analfabeto, 1o grau, 2o grau+e ignorado), de acordo com as informações registradas no banco de dados fornecido pela Coordenação Nacional de DST e AIDS. Em virtude das modificações nos códigos de escolaridade entre 1992
Tabela 1

Agrupamentos das condições clínicas quando da notificação dos casos de AIDS entre indivíduos maiores de 12 anos de idade, e suas denominações utilizadas nesta análise.

\begin{tabular}{ll}
\hline Condição na notificação & Denominação \\
\hline 1) Sarcoma de Kaposi & SK \\
2) Tuberculose pulmonar ou disseminada & Tuberculose \\
3) Candidíase em qualquer localização & Candidíase \\
4) Herpes zoster ou simplex & Herpes \\
5) Criptococose extra-pulmonar & Criptococose \\
6) Pneumonia por Pneumocystis carinii & PCP \\
7) Toxoplasmose cerebral & Neurotoxo \\
8) Infecções por Criptosporidium ou Isospora & Protozoários \\
\hline
\end{tabular}

e 1994, não foi possível distinguir entre os níveis 2 o grau e Superior de forma homogênea, tendo sido agrupados como 2 o grau +. Para as categorias de exposição múltipla, usou-se de hierarquização baseada na probabilidade de transmissão. Foram categorizados como UDI quando havia qualquer menção de UDI; como homo/bissexual, quando havia qualquer menção desta prática, exceto UDI; como transmissão sangüínea, quando havia qualquer menção de hemotransfusão, exceto UDI e prática ho$\mathrm{mo} /$ bissexual; como heterossexual, quando esta era o único relato de risco.

A nálise descritiva global dos casos de AIDS

De 1980 até 29 de maio de 1999 foram notificados 157.775 casos de AIDS entre indivíduos com 12 ou mais anos de idade ( $99 \%$ do total). A Tabela 1 mostra a análise descritiva global destes casos. Houve predominância do sexo masculino $(77,1 \%)$, idade acima de 29 anos $(64,5 \%)$, categoria de exposição homo/ bissexual $(24,1 \%)$, residentes na região Sudeste $(69,7 \%)$ e com 10 grau de escolaridade (46,1\%). Chama a atenção o elevado percentual de informação ignorada quanto a esta variável $(25,7 \%)$.

A proporção de casos masculinos notificados caiu de $90,1 \%$, até 1988 , para $68,3 \%$, em 1998/ 99, evidenciando redução de $24 \%$; por sua vez, entre as mulheres, a proporção de casos elevou-se de $9,9 \%$ para 31,7\% em 1998/ 99. A proporção de casos com 13-29 anos caiu de 37,3\%, até 1988, para 30,1\%, em 1998/99; já o grupo com 30 ou mais anos aumentou de $60,6 \%$ para $69,7 \%$, respectivamente. Quanto à categoria de exposição, houve incremento importan- 
te na transmissão heterossexual - de 5,8\%, até 1988, para 40,1\%, em 1998/ 99 -, enquanto, no grupo homo/bissexual, ocorreu redução de $59,2 \%$ para $20,9 \%$, respectivamente. A região Sudeste ainda persiste com a maior proporção de casos notificados, mas há também tendência de mudança. Até $1988,82,6 \%$ dos casos ocorreram nesta região, enquanto a segunda maior proporção foi registrada na região Sul (6,4\%). Já em 1998/99, 52,0\% dos casos ocorreram na região Sudeste, $24,0 \%$ na região Sul, $15,2 \%$ na região Nordeste, $5,8 \%$ na região Centro-Oeste e 3,0\% dos casos na região Norte ( Tabela 2).

Desde 1980 houve expressiva mudança no perfil de escolaridade dos casos notificados entre adultos e adolescentes. Incluindo os ignorados na análise, a proporção de casos entre analfabetos aumentou de $1,5 \%$, até 1988 , para 4,8\%, em 1998-99; entre aqueles com 1o grau, acresceu de $27,1 \%$ para $55,9 \%$ no mesmo período; e, entre aqueles com 2o graut, houve redução de $30,1 \%$ para $21,3 \%$ (Figura 1). Observa-se também diminuição na proporção daqueles com escolaridade ignorada (de $41,3 \%$ para $18,2 \%)$.

Ressalta-se, portanto, provável melhoria na qualidade de preenchimento das fichas de notificação, mas ainda persiste alta proporção de informação ignorada. Em razão dessa elevada proporção optou-se por realizar as análises de tendência por escolaridade, mantendo este grupo em separado. A conclusão a respeito do aumento de casos de AIDS entre aqueles com 1o grau, em particular, pode explicar-se, pelo menos em parte, como conseqüência da meIhoria das informações. Isto fica mais evidente quando se examina a semel hança das curvas "ignorado" e "2o grau+" e o aumento, quase que em relação inversa, da proporção com "10 grau". Os dados disponíveis (proporção) não permitem avaliar o risco de AIDS ou de infecção pelo HIV entre as populações com cada grau de escolaridade.

\section{A nálise das condições associadas}

\section{Descritiva}

A condição associada com maior incidência acumulada para o período 1980-1999 foi candidíase $(59,2 \%)$, seguida de tuberculose $(25,5 \%)$, PCP $(23,0 \%)$, neurotoxo (15,3\%), herpes (12,5\%), SK $(4,6 \%)$, criptococose $(4,5 \%)$ e protozoários (4,3\%) (Tabela 3). Os homens apresentaram maior incidência de todas as condições associadas, quando comparados com as mulheres.
Com exceção de candidíase e herpes, todas as diferenças foram estatisticamente significativas ( $p<0,01$ ). Os mais jovens (13-29 anos de idade) evidenciaram maior incidência para todas as condições, exceto para SK (5,2\% e 3,5\%, respectivamente $30+\mathrm{e}<30$ anos). As diferenças são pequenas, mas foram todas estatisticamente significativas, exceto herpes $(p=0,39)$ (Tabela 3).

Todas as categorias de exposição apresentaram igualmente diferenças estatisticamente significativas. A categoria homo/ bissexual mostrou as maiores incidências de PCP $(26,4 \%)$, herpes $(15,7 \%)$ e SK $(9,7 \%)$, enquanto criptococose $(5,1 \%)$, candidíase $(65,8 \%)$ e protozoários $(5,9 \%)$ tiveram maiores incidências entre aqueles com transmissão sangüínea. Os UDIs tiveram incidências mais el evadas de tuberculose e neurotoxo (32,9\% e 17,4\%, respectivamente).

Maior heterogeneidade entre as incidências das condições associadas foi encontrada para as regiões de residência, sendo as maiores e menores incidências de cada condição as seguintes: a) Maiores: candidíase (Nordeste, 63,5\%), tuberculose (Sudeste, 27,9\%), PCP (Centro-Oeste, $25,4 \%$ ), neurotoxo (Sudeste, 16,7\%), herpes (Sul, 13,5\%), SK (Sudeste, 4,9\%), criptococose (Sudeste, 5,0\%), e protozoários (Centro-Oeste, $7,9 \%)$; b) Menores: candidíase (Sul, 51,4\%), tuberculose (Centro-Oeste, 16,0\%), PCP (Norte, $15,7 \%$ ), neurotoxo (Sul, 10,1\%), herpes (Centro-Oeste, 10,7\%), SK (Sul, 3,5\%), criptococose (Nordeste, 1,4\%), e protozoários (Centro-Oeste, 3,7\%) (Tabela 3).

Quanto à escolaridade (Tabela 3) houve também diferenças expressivas na incidência acumulada das condições associadas. As maiores incidências de candidíase $(62,4 \%)$, PCP $(26,7 \%)$, herpes $(17,0 \%)$, SK $(7,9 \%)$, criptococose $(4,9 \%)$ e protozoários (5,3\%) ocorreram entre aqueles com melhor escolaridade (2o grau+). Para tuberculose, a maior incidência esteve entre os analfabetos $(30,1 \%)$ e, para neurotoxo, entre aqueles com escolaridade ignorada $(16,0 \%)$. Todas as diferenças foram estatisticamente significativas $(p<0,01)$.

\section{Tendências}

Comparando-se o período inicial (1980-88) e final (1998-99), houve redução na incidência de todas as condições associadas (Tabela 2). Decaiu de $62,3 \%$ a 43,8\% para candidíase; de $25,8 \%$ a $17,9 \%$ para tuberculose; de $27,7 \%$ a $11,9 \%$ para PCP; de $14,4 \%$ a $10,0 \%$ para neurotoxo; de $14,9 \%$ a $9,1 \%$ para herpes, de $11,4 \%$ a $2,1 \%$ para SK, de 6,6\% a 2,6\% para criptococose e de $6,2 \%$ a 2,2\% para protozoários. A Figura 6 
mostra a incidência das condições associadas entre os casos de AIDS notificados para cada ano e, por sua vez, a Tabela 4 apresenta as estimativas de inclinação (beta) obtidas através da regressão linear para cada condição, tanto de forma global quanto para cada variável estudada. Observa-se tendência de redução estatisticamente significativa $(p<0,05)$ na incidência global de todas as condições associadas (inclinação negativa), sendo as maiores quedas observadas para PCP (beta=-1,853) e candidíase (beta $=-1,243$ ), e as menores, para criptococose (beta $=-0,400$ ) e herpes (beta=-0,417). Esta propensão repete-se nas análises de tendência por sexo, idade, categoria de exposição, região e escolaridade, havendo alguma heterogeneidade entre as condições associadas.

Para candidíase, tuberculose e protozoários ocorreu maior redução entre as mulheres (betas $=-1,527 ;-1,293$; e - 0,495, respectivamente) do que entre os homens (betas $=-0,475 ;-1,199$; e -0,419, respectivamente) (Tabela 4). O inverso - maior redução entre homens - teve lugar com SK, herpes e neurotoxo, enquanto a redução para PCP foi muito semelhante. Todas as tendências foram estatisticamente diferentes de zero, com exceção de neurotoxo, em que a redução entre as mulheres foi pequena e não significativa ( $p=0,226)$. Dentre todas as condições, a maior redução ocorreu para PCP entre os homens (beta $=-1,806$ ) e a menor, para SK, entre as mulheres (beta $=-0,127$ ). Quanto à idade, os mais jovens (13-29 anos) apresentaram maiores reduções para candidíase, tuberculose, $\mathrm{PCP}$, neurotoxo e herpes, ao passo que aqueles com 30+anos apresentaram mai ores reduções para SK, criptococose e protozoários. A maior redução ocorreu para PCP entre os mais jovens (beta $=-1,989$ ), e a menor, para herpes entre os mais velhos (beta $=-0,342$ ) (Tabela 4).

Todas as categorias de exposição mostraram reduções em todas as condições associadas, exceto herpes entre aqueles com transmissão sangüínea (beta $=0,153$ ) e neurotoxo entre aqueles da categoria "outros/ignorado" (beta $=0,115)$, o que, de fato, constitui aumento. As maiores reduções ocorreram para PCP (beta $=-2,053,-2,011$ e-1,925 para, respectivamente, heterossexuais, homo/bissexuais e UDI), seguido de candidíase (beta =-1,261, - 1,027 e $-1,053$, para, respectivamente, heterossexuais, outros/ignorados e UDI). A categoria transmissão sangüínea apresentou inclinações não significativas para a maioria das condições, provavelmente em virtude dos pequenos números deste grupo.

Com relação às regiões, também houve diminuição na incidência da maioria das condi-
Tabela 2

Análise descritiva dos casos de AIDS entre indivíduos maiores de 12 anos notificados ao Ministério da Saúde ( $n=157.775)$, Brasil, acumulado (1980-1999) e para períodos inicial e final.

\begin{tabular}{|c|c|c|c|c|}
\hline \multirow[t]{2}{*}{ Características } & \multicolumn{2}{|c|}{ Acumulado } & \multicolumn{2}{|c|}{$\%$ Inicial e final } \\
\hline & $\mathrm{n}$ & $\%$ & $1980-88$ & 1998-99 \\
\hline \multicolumn{5}{|l|}{ 1) Sexo } \\
\hline Masculino & 121.708 & $(77,1)$ & $(90,1)$ & $(68,3)$ \\
\hline Feminino & 36.067 & $(22,9)$ & $(9,9)$ & $(31,7)$ \\
\hline \multicolumn{5}{|l|}{ 2) Idade } \\
\hline $13-29$ & 55.266 & $(35,0)$ & $(37,3)$ & $(30,1)$ \\
\hline $30+$ & 101.764 & $(64,5)$ & $(60,6)$ & $(69,7)$ \\
\hline Ignorado & 745 & $(0,5)$ & $(2,1)$ & $(0,2)$ \\
\hline \multicolumn{5}{|l|}{ 3) Exposição } \\
\hline Heterossexual & 38.084 & $(24,1)$ & $(5,8)$ & $(40,1)$ \\
\hline Homo/Bissexual & 43.210 & $(27,4)$ & $(59,2)$ & $(20,9)$ \\
\hline UDI & 37.186 & $(23,6)$ & $(13,5)$ & $(16,5)$ \\
\hline Sangue & 3.961 & $(2,5)$ & $(6,7)$ & $(3,8)$ \\
\hline O utros/Ignorado & 35.334 & $(22,4)$ & $(14,8)$ & $(22,3)$ \\
\hline \multicolumn{5}{|l|}{ 4) Região } \\
\hline Centro-O este & 8.014 & $(5,1)$ & $(3,2)$ & $(5,8)$ \\
\hline Nordeste & 14.596 & $(9,3)$ & $(6,9)$ & $(15,2)$ \\
\hline Norte & 2.865 & $(1,8)$ & $(0,8)$ & $(3,0)$ \\
\hline Sudeste & 109.941 & $(69,7)$ & $(82,6)$ & $(52,0)$ \\
\hline Sul & 22.323 & $(14,1)$ & $(6,5)$ & $(24,0)$ \\
\hline \multicolumn{5}{|l|}{ 5) Escolaridade } \\
\hline Analfabeto & 5.542 & $(3,5)$ & $(1,5)$ & $(4,8)$ \\
\hline 1o Grau & 72.692 & $(46,1)$ & $(27,1)$ & $(55,9)$ \\
\hline 2o Grau+ & 38.756 & $(24,6)$ & $(30,1)$ & $(21,3)$ \\
\hline Ignorado & 40,875 & $(25,7)$ & $(41,3)$ & $(18,2)$ \\
\hline \multicolumn{5}{|c|}{ 6) Condições associadas1 } \\
\hline Candidíase & 93.599 & $(59,3)$ & $(62,3)$ & $(43,9)$ \\
\hline Tuberculose & 40,185 & $(25,5)$ & $(25,8)$ & $(17,9)$ \\
\hline PCP & 36.339 & $(23,0)$ & $(27,7)$ & $(11,9)$ \\
\hline Neurotoxo & 24.068 & $(15,3)$ & $(14,5)$ & $(10,0)$ \\
\hline Herpes & 19.675 & $(12,5)$ & $(14,9)$ & $(9,1)$ \\
\hline SK & 7.340 & $(4,6)$ & $(11,4)$ & $(2,1)$ \\
\hline Criptococose & 7.160 & $(4,5)$ & $(6,6)$ & $(2,6)$ \\
\hline Protozoários & 6.901 & $(4,3)$ & $(6,2)$ & $(2,2)$ \\
\hline
\end{tabular}

1 Vide Tabela 1. 
Figura 1

Distribuição dos casos de AIDS notificados em maiores de 12 anos, por ano e escolaridade, Brasil, 1980-1999.

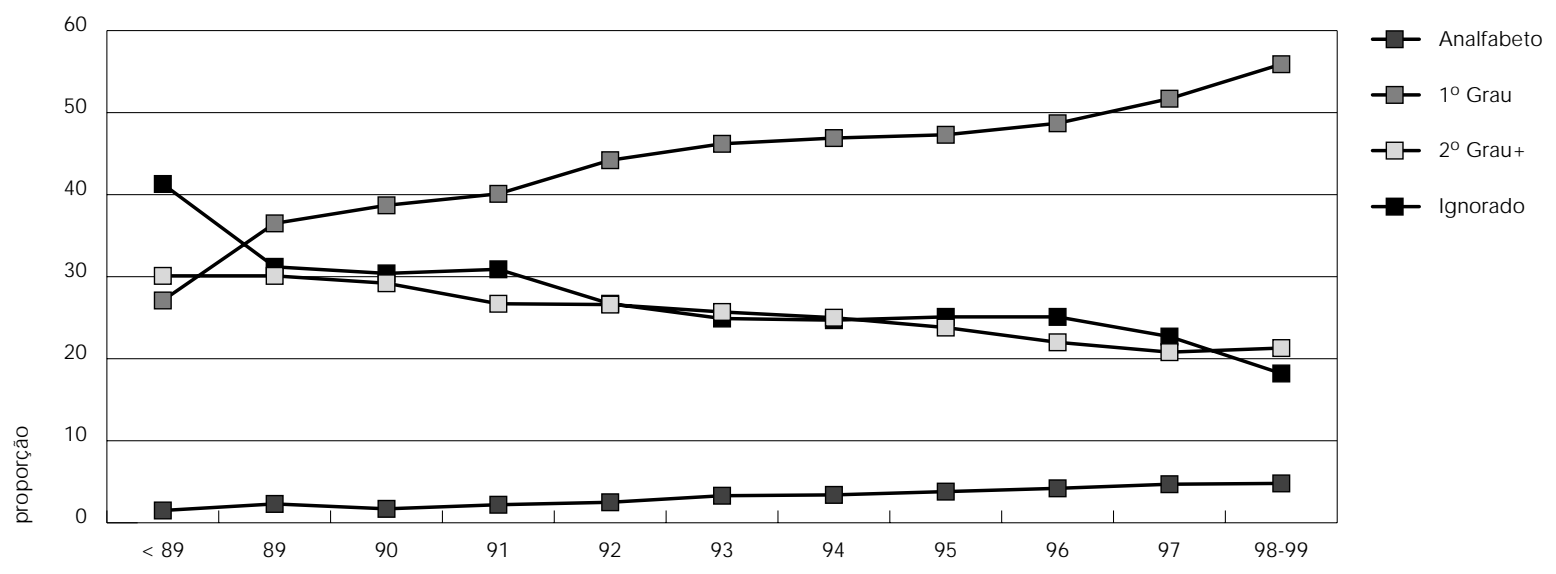

ções associadas, porém não de forma homogênea. As maiores reduções ocorreram, na região Norte, para SK, herpes, criptococose, PCP, neurotoxo e protozoários, ao passo que, na região Sudeste, para tuberculose e candidíase; as menores reduções, na região Nordeste, ocorreram para SK e protozoários; na Centro-Oeste, para candidíase, herpes e criptococose; e, na região Sudeste, para PCP. Chama a atenção o aumento na incidência de tuberculose na região Nordeste (beta $=0,393$ ) e de neurotoxo na região Centro-Oeste(beta $=0,204$ ), apesar de nenhum destes dois aumentos ser estatisticamente diferente de zero $(p>0,05)$. De todas as regiões, a maior redução ocorreu para PCP na região Norte (beta $=-4,251$ ) e a menor, para tuberculose na região Nordeste, o que, de fato, foi aumento (beta $=0,393$ ).

\section{Condições associadas e escolaridade}

Todas as condições associadas apresentaram distribuição por escolaridade semelhante àquela do total de casos de AIDS notificados (Figura 1). Há tendência de aumento da proporção de indivíduos analfabetos e com 10 grau, enquanto aqueles com 2 o grau +e os ignorados exibiram propensão de queda. A título de ilustração, estão mostradas de forma gráfica apenas as condições associadas "tuberculose" e "PCP" (Figuras 2 e 3). De forma semelhante à tendência global, a incidência das oito condições associadas estudadas indica queda em todas as categorias de escolaridade, em especial, a partir de 1995. No entanto, há al guma heterogeneidade que merece ser detalhada.

A tuberculose mostrou um quadro de tendência de queda semelhante (beta $\cong-1,0$ ) para analfabetos, com 1o grau ou 2 o grau + . A redução foi menor (beta $=-0,372$ ) no grupo ignorado (Tabela 4). No entanto, fica claro que a incidência é maior, para todos os anos, entre os analfabetos, seguida daqueles com 1o grau (Figura 4), sendo que, entre 1990 e 1994, houve aumento da incidência de tuberculose neste último grupo. As menores incidências foram registradas para aqueles com 20 grau+de escolaridade. Conseqüentemente observa-se aumento importante da RI entre os períodos inicial e final tanto para os analfabetos (de 1,82 para 1,89 ) quanto para aqueles com 1 o grau (de $1,50$ para 1,76$)$, quando comparados com o 20 grau+(Tabela 5).

Já a incidência de PCP foi maior, em todos os anos, entre aqueles com maior escolaridade (2o grau ou mais) (Tabela 4). Nota-se aumento da incidência até 1991, com queda mais acentuada a partir desse ano (Figura 5). No entanto, a tendência também é de queda, sendo os analfabetos aqueles que apresentaram a maior redução (beta $=-2,148$ ). Além disto, as RIs, para os períodos inicial e final, indicam menor risco para os analfabetos e aqueles com 10 grau ( RI =0,79 em 1998/ 99) (Tabela 5).

A incidência de candidíase foi semel hante para as quatro categorias de escolaridade, em todos os anos, com redução também seme- 
Incidência acumulada (por 100 casos de AIDS)1 das condições associadas, de acordo com variáveis selecionadas, quando da notificação ao Ministério da Saúde, entre indivíduos maiores de 12 anos, por regiões, Brasil, 1980-1999.

\begin{tabular}{|c|c|c|c|c|c|c|c|c|}
\hline Categoria (n) & Candidíase & Tuberculose & PCP & Neurotoxo & Herpes & SK & Criptococose & Protozoários \\
\hline Global & 59,2 & 25,5 & 23,0 & 15,3 & 12,5 & 4,6 & 4,5 & 4,3 \\
\hline \multicolumn{9}{|l|}{ Sexo } \\
\hline Masculino (121.708) & 59,3 NS & $26,5^{*}$ & $24,0 *$ & $15,5^{*}$ & $12,5 \mathrm{NS}$ & $5,6 *$ & $4,9 *$ & $4,5^{*}$ \\
\hline Feminino (36.067) & 59,2 & 22,0 & 19,9 & 14,4 & 12,2 & 1,5 & 3,3 & 3,9 \\
\hline \multicolumn{9}{|l|}{ Idade (anos) } \\
\hline$<30(55.266)$ & $59,7^{*}$ & $26,6 *$ & $23,4 *$ & $16,1^{*}$ & $12,6 \mathrm{NS}$ & $3,5^{*}$ & $4,9 *$ & $4,5^{*}$ \\
\hline $30+(101.764)$ & 59,2 & 24,8 & 22,9 & 14,8 & 12,4 & 5,2 & 4,3 & 4,3 \\
\hline \multicolumn{9}{|l|}{ Exposição } \\
\hline Heterossexual (38.084) & $61,7^{*}$ & $22,7^{*}$ & $20,4^{*}$ & $13,5^{*}$ & $12,8^{*}$ & $2,5^{*}$ & $3,6^{*}$ & $4,1^{*}$ \\
\hline Homo/Bissexual (43.210) & 64,0 & 23,7 & 26,4 & 15,1 & 15,7 & 9,7 & 5,0 & 5,7 \\
\hline UDI (37.186) & 64,4 & 32,9 & 25,5 & 17,4 & 12,5 & 2,3 & 5,1 & 4,3 \\
\hline Sangue (3.961) & 65,8 & 24,6 & 23,9 & 14,3 & 14,8 & 2,7 & 5,1 & 5,9 \\
\hline O utros/Ignorado (35.334) & 46,6 & 23,7 & 19,8 & 15,8 & 8,1 & 1,9 & 4,6 & 3,0 \\
\hline \multicolumn{9}{|l|}{ Região } \\
\hline Centro-O este (8.014) & $54,3^{*}$ & $16,0 *$ & $25,4 *$ & $12,5^{*}$ & $10,7^{*}$ & $4,4 *$ & $4,1^{*}$ & $7,9 *$ \\
\hline Nordeste (14.596) & 63,5 & 22,0 & 18,1 & 13,0 & 11,5 & 4,6 & 1,4 & 6,0 \\
\hline Norte $(2.865)$ & 61,5 & 26,7 & 15,7 & 14,8 & 12,1 & 3,6 & 2,7 & 5,5 \\
\hline Sudeste (109.941) & 60,7 & 27,9 & 24,3 & 16,7 & 12,5 & 4,9 & 5,0 & 4,0 \\
\hline Sul (22.323) & 51,4 & 19,1 & 20,1 & 10,1 & 13,5 & 3,5 & 4,7 & 3,7 \\
\hline \multicolumn{9}{|l|}{ Escolaridade } \\
\hline 2o Grau+ (38.756) & $62,4 *$ & $20,5^{*}$ & $26,7^{*}$ & $14,1^{*}$ & $17,0 *$ & $7,9 *$ & $4,9 *$ & $5,3^{*}$ \\
\hline 10 Grau (72.692) & 61,5 & 28,0 & 22,1 & 15,7 & 12,2 & 3,2 & 4,3 & 4,3 \\
\hline Analfabeto (5.542) & 59,2 & 30,1 & 17,3 & 11,7 & 11,3 & 3,1 & 2,9 & 4,5 \\
\hline Ignorado (40.875) & 52,5 & 24,9 & 21,8 & 16,0 & 8,8 & 4,4 & 4,9 & 3,6 \\
\hline
\end{tabular}

1 Denominador $=$ número de casos de AIDS em cada categoria.

* Estatisticamente significativo, NS = Não significativo.

Ihante (beta $>-1,0)$ e significativa $(p \varangle 0,01)$ (Tabela 4). A partir de 1996, a incidência de candidíase é discretamente mai or entre os analfabetos do que nas outras categorias. Quando se compara o período inicial (1980-88) com o final (1998-99), verifica-se aumento na razão das incidências de candidíase de 1,05 para 1,10 e de 1,01 para 1,09 entre analfabetos e 1o grau, respectivamente, quando comparados com os de 2 o grau +(Tabela 5), i.e., há discreto aumento no risco de candidíase ao final do período para os analfabetos e aqueles com 1o grau.

Para neurotoxo, a maior redução ocorreu entre aqueles com melhor escolaridade (beta $=-0,918)$, enquanto o grupo de informação ignorada apresentou, na verdade, tendência de aumento (beta $=0,043$ ), apesar deste não ser estatisticamente significativo. A menor inci- dência em 1998/ 99 ocorreu entre aqueles com melhor escolaridade, indicando RI de 1,17 para os analfabetos e de 1,48 para aqueles com 1 응 grau (Tabela 5).

Quanto ao herpes, para todos os anos, a incidência foi maior entre aqueles com melhor escolaridade; a menor redução ocorreu entre aqueles com 1 o grau (beta $=-0,338$ ), ao passo que, em 1998/99, as incidências foram próximas $(9,8 \%, 9,5 \%$ e $10,8 \%$ para, respectivamente, analfabetos, 10 grau e 20 grau+). Há inversão da RI entre os períodos inicial e final para os analfabetos (de 1,30 para 0,91) (Tabela 5).

A incidência de SK mostrou quadro interessante. No início do período, o diferencial entre as incidências era maior $(R I=0,45$ e 0,51 para os anal fabetos e com 1o grau comparado com aqueles com 2o grau+, respectivamente). Já em 
Inclinações estimadas ${ }^{1}$ das tendências temporais da incidência das condições associadas, quando da notificação ao Ministério da Saúde, entre indivíduos maiores de 12 anos, por regiões, Brasil, 1980-1999.

\begin{tabular}{|c|c|c|c|c|c|c|c|c|}
\hline Categoria (n) & Candidíase & Tuberculose & PCP & Neurotoxo & Herpes & SK & Criptococose & Protozoários \\
\hline Global & $-1,243^{*}$ & $-0,689 *$ & $-1,853^{*}$ & $-0,507 *$ & $-0,417^{*}$ & $-0,772 *$ & $-0,400 *$ & $-0,434 *$ \\
\hline \multicolumn{9}{|l|}{ Sexo } \\
\hline Masculino & $-1,199 *$ & $-0,475^{*}$ & $-1,806^{*}$ & $-0,534 *$ & $-0,438 *$ & $-0,809 *$ & $-0,397 *$ & $-0,419 *$ \\
\hline Feminino & $-1,527 *$ & $-1,293^{*}$ & $-1,804 *$ & $-0,289 \mathrm{NS}$ & $-0,292 *$ & $-0,127 *$ & $-0,242 *$ & $-0,495^{*}$ \\
\hline \multicolumn{9}{|l|}{ Idade (anos) } \\
\hline$<30$ & $-1,402 *$ & $-0,923^{*}$ & $-1,989 *$ & $-0,582 *$ & $-0,571 *$ & $-0,576 *$ & $-0,396 *$ & $-0,396 *$ \\
\hline $30+$ & $-1,183^{*}$ & $-0,522^{N S}$ & $-1,832 *$ & $-0,462 *$ & $-0,342 *$ & $-0,910 *$ & $-0,405^{*}$ & $-0,458 *$ \\
\hline \multicolumn{9}{|l|}{ Exposição } \\
\hline Heterossexual & $-1,261^{\mathrm{NS}}$ & $-0,867^{*}$ & $-2,053^{*}$ & $-0,499 *$ & $-0,278$ & $-0,430 *$ & $-0,350 *$ & $-0,560 *$ \\
\hline Homo/Bissexual & $-0,898 \mathrm{NS}$ & $-0,855^{*}$ & $-2,011^{*}$ & $-0,820 *$ & $-0,346^{*}$ & $-0,964 *$ & $-0,521 *$ & $-0,454 *$ \\
\hline UDI & $-1,027 \mathrm{NS}$ & $-0,772 *$ & $-1,925^{*}$ & $-0,472$ NS & $-0,199 \mathrm{NS}$ & $-0,104 *$ & $-0,201 *$ & $-0,277^{*}$ \\
\hline Sangue & $-0,359 \mathrm{NS}$ & $-0,567 \mathrm{NS}$ & $-0,567 \mathrm{NS}$ & $-0,635^{*}$ & $0,153 \mathrm{NS}$ & $-0,199 \mathrm{NS}$ & $-0,568 *$ & $-0,727^{*}$ \\
\hline O utros/Ignorado & $-1,053^{*}$ & $-0,171 \mathrm{NS}$ & $-0,767^{*}$ & $0,115 \mathrm{NS}$ & $-0,250 *$ & $-0,614^{*}$ & $-0,255^{*}$ & $-0,260 *$ \\
\hline \multicolumn{9}{|l|}{ Região } \\
\hline Centro-O este & $-0,105 \mathrm{NS}$ & $-0,168 \mathrm{NS}$ & $-2,737^{*}$ & $0,204 \mathrm{NS}$ & $-0,029 \mathrm{NS}$ & $-0,683^{*}$ & $-0,171^{N S}$ & $-0,999 *$ \\
\hline Nordeste & $-0,231^{N S}$ & $0,393 \mathrm{NS}$ & $-2,173^{*}$ & $-0,404 *$ & $-0,458^{*}$ & $-0,662 *$ & $-0,189 *$ & $-0,237^{*}$ \\
\hline Norte & $-0,148 \mathrm{NS}$ & $-0,608 \mathrm{NS}$ & $-4,251 *$ & $-0,529 \mathrm{NS}$ & $-0,959 \mathrm{NS}$ & $-1,064 *$ & $-0,513 \mathrm{NS}$ & $-1,514 *$ \\
\hline Sudeste & $-1,413 \mathrm{NS}$ & $-0,634 \mathrm{NS}$ & $-1,604 *$ & $-0,482^{*}$ & $-0,399 *$ & $-0,796^{*}$ & $-0,437^{*}$ & $-0,417^{*}$ \\
\hline Sul & $-0,422 \mathrm{NS}$ & $-0,485 \mathrm{NS}$ & $-2,717^{*}$ & $-0,253 \mathrm{NS}$ & $-0,598^{*}$ & $-0,684 *$ & $-0,251^{*}$ & $-0,484 *$ \\
\hline \multicolumn{9}{|l|}{ Escolaridade } \\
\hline 2o Grau+ & $-1,368 *$ & $-0,958 *$ & $-2,019 *$ & $-0,918^{*}$ & $-0,647^{*}$ & $-1,117^{*}$ & $-0,583^{*}$ & $-0,600 *$ \\
\hline 1o Grau & $-1,444^{*}$ & $-1,078 *$ & $-1,993^{*}$ & $-0,637^{*}$ & $-0,338 *$ & $-0,502 *$ & $-0,448 *$ & $-0,438 *$ \\
\hline Analfabeto & $-1,320 *$ & $-0,968 *$ & $-2,148 *$ & $-0,764^{*}$ & $-0,710 *$ & $-0,404 *$ & $-0,380 *$ & $-0,488 *$ \\
\hline Ignorado & $-1,373^{*}$ & $-0,372 \mathrm{NS}$ & $-1,324 *$ & $0,043 \mathrm{NS}$ & $-0,363^{*}$ & $-0,672 *$ & $-0,150 *$ & $-0,324 *$ \\
\hline
\end{tabular}

1 Regressão linear simples.

* Estatisticamente diferente de zero, NS = Não significativo.

1998/ 99, essa relação é mais próxima de $1(\mathrm{RI}=$ 0,72 e 0,59 para os analfabetos e com 10 grau, comparados com aqueles com 20 grau+, respectivamente). Isto se deveu principalmente à maior redução do grupo com melhor escolaridade (beta $=-1,117$ ).

Os dois últimos grupos apresentam queda mais acentuada entre aqueles com melhor escolaridade (beta $=-0,600$ e -0,583 para, respectivamente, criptococose e protozoários). Os valores também tendem a aproximar-se ao final do período. Além disto, a propensão foi de maior risco destas condições para o período final entre os analfabetos e aqueles com 10 grau, em relação ao 2 o grau+(Tabela 5).

A Tabela 6 mostra síntese da tendência das condições associadas para a variável escolaridade. Houve forte tendência (beta >-1,0) de que- da na incidência global de candidíase e PCP, tendência intermediária (beta $=-0,50 \mathrm{a}-1,0$ ) de queda para tuberculose, neurotoxo e SK e tendência mais fraca de queda (beta $<-0,50$ ) para herpes, criptococose e protozoários. Quatro das condições tiveram as maiores reduções entre aqueles com 20 grau+, enquanto apenas uma das menores reduções ocorreu neste grupo (tuberculose). Além disto, há indicação de maior risco para os analfabetos e 1o grau da maioria das condições associadas (candidíase, tuberculose, neurotoxo, SK, criptococose, protozoários), e menor risco para PCP e herpes (analfabetos) (Tabela 5).

Considerando todas as variáveis (Tabela 4), as maiores reduções para cada condição ocorreram entre aqueles com 1 o grau, para candidíase; no sexo feminino, para tuberculose; na 
Figura 2

Distribuição dos diagnósticos de tuberculose, por ano e escolaridade, entre casos de AIDS notificados em maiores de 12 anos, Brasil, 1980-1999.
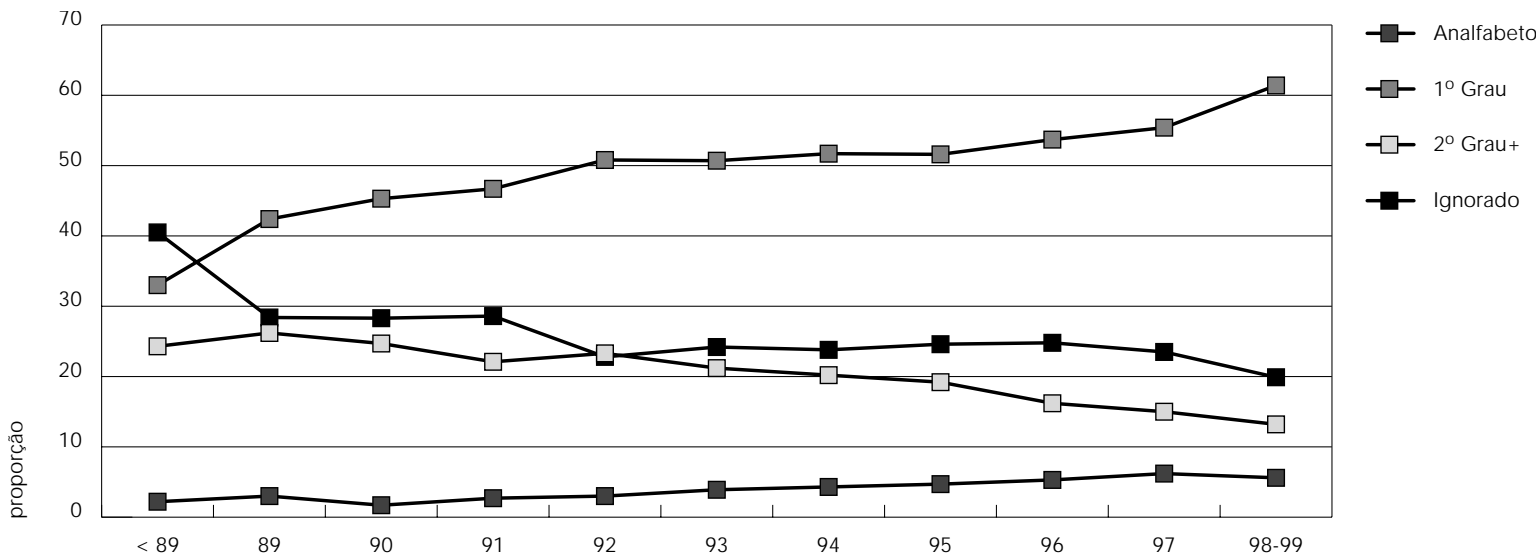

Figura 3

Distribuição dos casos de PCP, por ano e escolaridade, entre casos de AIDS notificados em maiores de 12 anos, Brasil, 1980-1999.
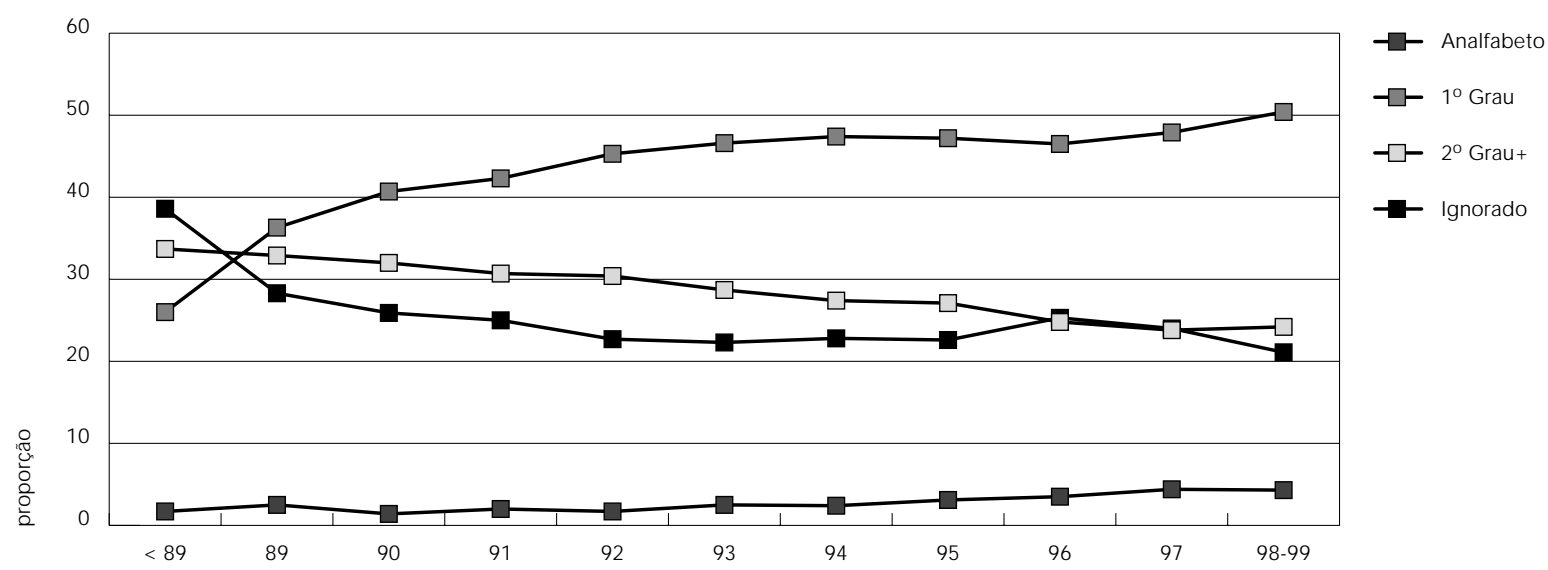
Figura 4

Incidência (por 100) de tuberculose entre os casos de AIDS notificados em maiores de 12 anos, por ano e escolaridade, Brasil, 1980-1999.

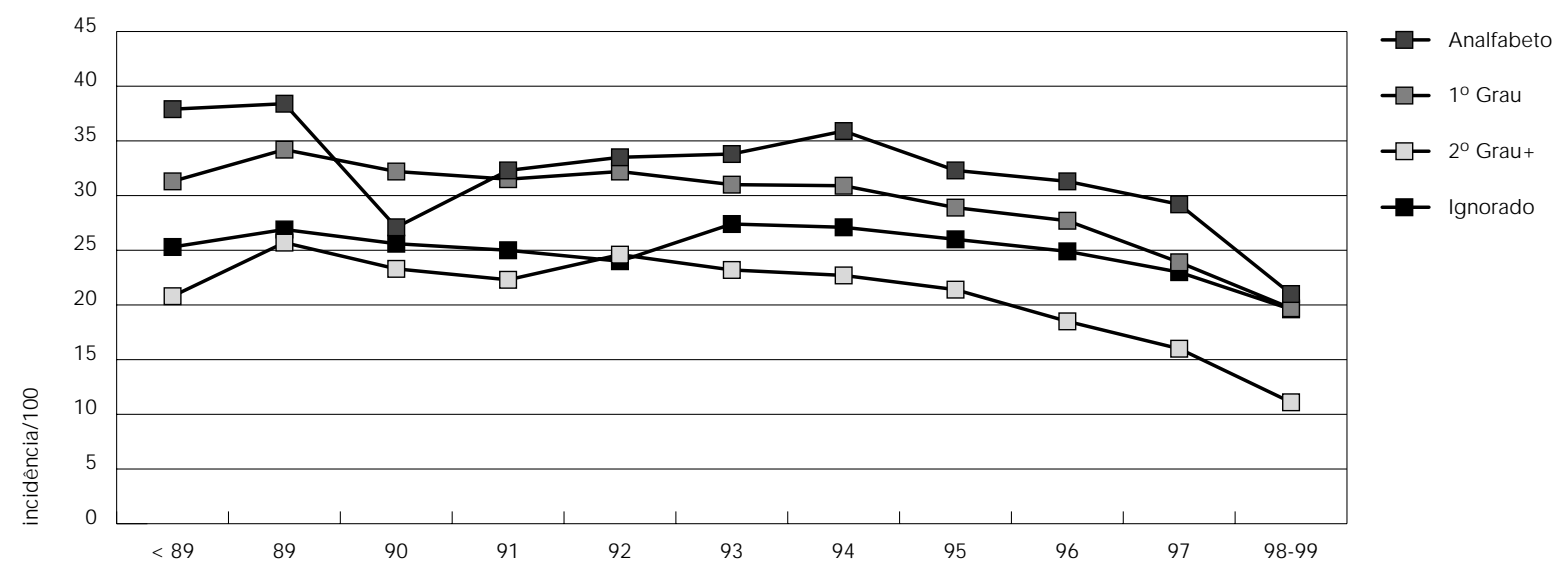

região Norte, para PCP; entre aqueles com 20 grau +, para neurotoxo; na região Norte, para herpes; entre os de 20 grau+, para SK e criptococose; e, na região Norte, para protozoários. As menores reduções ocorreram, na região Centro-Oeste, para candidíase; na categoria de exposição transmissão sangüínea, para tuberculose, PCP e herpes; na região Centro-Oeste, para neurotoxo; entre os UDIs, para SK; entre aqueles com escolaridade ignorada, para criptococose e, na região Nordeste, para protozoários.

\section{Comentários}

\section{Qualidade dos dados}

Dados secundários tendem a ter confiabilidade mais baixa do que aqueles obtidos através de coleta primária, quando os instrumentos são testados e os entrevistadores, treinados. Observam-se elevadas proporções de informações ignoradas, em particular, para escolaridade e categoria de exposição. Além de alta proporção, verifica-se que as informações ausentes não são constantes ao longo do tempo, havendo tendência de redução no caso da variável escolaridade. Se, por um lado, isto pode indicar melhoria na qualidade do preenchimento da ficha de notificação, por outro lado, pode também indicar que o aumento proporcional das outras categorias, em particular, 1o grau, deve-se a esta dinâmica e não necessariamen- te a um aumento real, conseqüência advinda de utilizar-se proporção em lugar de coeficientes por população em análises de tendência temporal. Outra limitação do dado secundário é o erro de classificação, mais factível de ocorrer com as categorias de exposição. No entanto, este pode também estar operando com a variável escolaridade, principalmente se a notificação ocorrer muito tempo após a primeira consulta, quando os dados sócio-demográficos tendem a ser coletados (cadastro inicial). A não ser que o profissional responsável pela notificação entreviste novamente o paciente, tendese a registrar o grau de escolaridade por ocasião da primeira consulta e não quando da notificação. Apenas estudos de confiabilidade poderiam avaliar a existência e o grau de magnitude desses erros, gerando estimativas que poderiam ser utilizadas para fazer análises de tendência corrigidas.

Os dados referentes às condições associadas também devem ser vistos com cautela quanto a sua confiabilidade. Primeiro, não existe instrução absolutamente clara no que concerne ao momento a que se refere a ficha de notificação para indicar quais condições associadas devem ser registradas. Se, em tese, deveriam ser indicadas apenas aquelas que ocorreram no momento da notificação, na prática é comum registrarem-se as condições que ocorreram até aquele momento, em especial, quando o paciente já se encontra em fase avançada por ocasião da primeira consulta. Neste caso, 
Tabela 5

Razão das Incidências (RI) das condições associadas, no início (até 1988) e no final do período (1998/99),

comparando Analfabeto e 10 Grau com 20 Grau+.

\begin{tabular}{|c|c|c|c|c|c|c|}
\hline \multirow[t]{2}{*}{ Condições associadas } & \multicolumn{3}{|c|}{ RI Analfabeto } & \multicolumn{3}{|c|}{ RI 1ㅇ Grau } \\
\hline & inicial & final & tendência* & inicial & final & tendência* \\
\hline Candidíase & 1,05 & 1,10 & $\uparrow$ & 1,01 & 1,09 & $\uparrow$ \\
\hline Tuberculose & 1,82 & 1,89 & $\uparrow$ & 1,50 & 1,76 & $\uparrow \uparrow$ \\
\hline$P C P$ & 1,03 & 0,79 & $\downarrow \downarrow$ & 0,86 & 0,79 & $\downarrow$ \\
\hline Neurotoxo & 1,02 & 1,17 & $\uparrow \uparrow$ & 1,04 & 1,48 & $\uparrow \uparrow$ \\
\hline Herpes & 1,30 & 0,91 & $\downarrow \downarrow$ & 0,69 & 0,87 & $\uparrow \uparrow$ \\
\hline SK & 0,45 & 0,72 & $\uparrow \uparrow$ & 0,51 & 0,59 & $\uparrow$ \\
\hline Criptococose & 0,56 & 1,06 & $\uparrow \uparrow$ & 0,82 & 1,21 & $\uparrow \uparrow$ \\
\hline Protozoários & 1,20 & 1,59 & $\uparrow \uparrow$ & 0,99 & 1,14 & $\uparrow \uparrow$ \\
\hline
\end{tabular}

$\mathrm{RI}=$ Razão da incidência (referência $=2 \underline{0} \mathrm{Grau}+$ ).

$* \uparrow$ ou $\downarrow=$ aumenta ou diminui em $<10 \%$ entre a inicial e a final.

$\uparrow \uparrow$ ou $\downarrow \downarrow$ = aumenta ou diminui em $>10 \%$ entre a inicial e a final.

Figura 5

Incidência de PCP, por ano e escolaridade, entre os casos de AIDS notificados em maiores de 12 anos,

Brasil, 1980-1999.

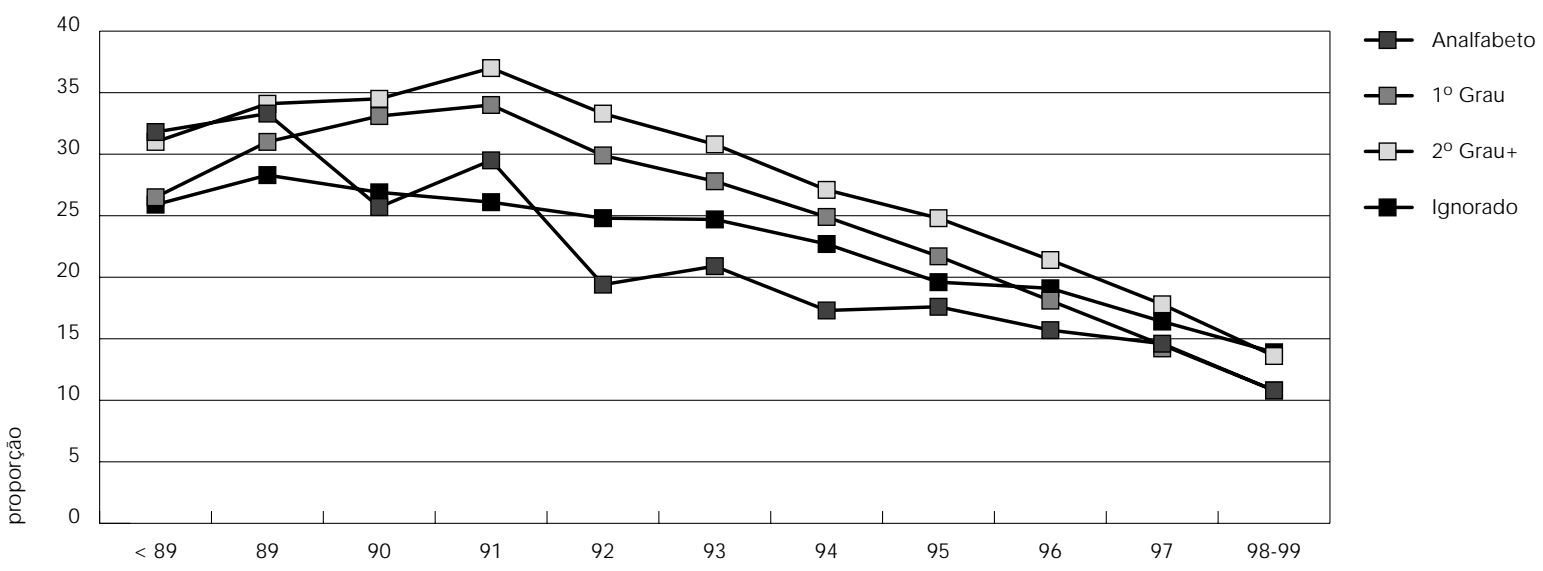

confundem-se condições marcadoras com condições subseqüentes à progressão clínica para AIDS. Uma das conseqüências disso seria o aumento artificial do número de casos de certas condições, talvez menos graves, que ocorreram anteriormente, mas que não geraram busca do atendimento médico (e.g. candidíase e herpes). Além disto, em geral, é registrado na ficha de notificação o dado positivo, i.e., a condição existente, deixando-se em branco aquelas não existentes. Da mesma forma, a informação ig- norada ora é indicada como tal, ora como não tendo ocorrido e, às vezes, é simplesmente deixada em branco. Isto gera um banco de dados com grande quantidade de informações com baixa confiabilidade. Levando-se em conta esta prática clínica de valorizar apenas o dado positivo, nesta análise tomou-se em conta, como condição presente, apenas aquelas indicadas; o restante foi considerado como não tendo a condição. Outro fator que deve preocupar é o fato de o registro das informações ser ape 
Síntese das tendências temporais da incidência das condições associadas, com relação à escolaridade.

\begin{tabular}{|c|c|c|c|c|c|}
\hline & $\begin{array}{l}\text { Tendência } \\
\text { global* }\end{array}$ & $\begin{array}{l}\text { Maior } \\
\text { redução }\end{array}$ & $\begin{array}{l}\text { Menor } \\
\text { redução }\end{array}$ & $\begin{array}{l}\text { Extensão da } \\
\text { inclinação }\end{array}$ & $\begin{array}{l}\text { Maior incidência } \\
\text { média }\end{array}$ \\
\hline Candidíase & $\downarrow \downarrow \downarrow$ & 10 G rau & Analf. & $-1,32$ a $-1,44$ & 20 Grau+ \\
\hline Tuberculose & $\downarrow \downarrow$ & $10 \mathrm{Grau}$ & 2o Grau+ & $-0,96$ a $-1,08$ & Analf. \\
\hline $\mathrm{PCP}$ & $\downarrow \downarrow \downarrow$ & Analf. & 10 G rau & $-1,99$ a $-2,15$ & 2o Grau+ \\
\hline Neurotoxo & $\downarrow \downarrow$ & 20 Grau+ & 10 G rau & $-0,64$ a $-0,92$ & 10 G rau \\
\hline Herpes & $\downarrow$ & Analf. & 1o Grau & $-0,34$ a $-0,71$ & 2ㅇ Grau+ \\
\hline SK & $\downarrow \downarrow$ & 2ㅇ Grau+ & Analf. & $-0,40$ a $-1,12$ & 2ㅇ Grau+ \\
\hline Criptococose & $\downarrow$ & 2o Grau+ & Analf. & $-0,38$ a $-0,58$ & 2o Grau+ \\
\hline 1o Grau & $\downarrow$ & 2o Grau+ & 1o Grau & $-0,44$ a $-0,60$ & 2o Grau+ \\
\hline
\end{tabular}

*Indicam reduções na inclinação: $\downarrow=<-0,50 ; \downarrow \downarrow=-0,50$ a $-1,00 ; \downarrow \downarrow \downarrow=>-1,0$.

nas sufici entes para atingir os dez pontos necessários à notificação. Nestes últimos dois casos, a conseqüência seria a subestimativa da incidência de cada condição.

Outro fator importante são as condições de atendimento e diagnóstico dos serviços de referência. É provável que exista grande heterogeneidade nos diversos serviços de referência a nível nacional. Muitos dos diagnósticos notificados são provavelmente presuntivos, clínicos e / ou baseados em resposta terapêutica. Como exemplo, podemos citar o diagnóstico diferencial entre tuberculose pulmonar e pneumonias por P. cari ni i, os diagnósticos laboratoriais de isospora e criptosporidium e os diagnósticos diferenciais de algumas condições neurológicas, tais como neurotoxoplasmose e meningite criptocócica. Esta provável imprecisão diagnóstica justifica-se pela falta de apoio propedêutico e/ ou condições técnicas locais (e.g. fibrobroncoscopia com lavado broncoalveolar, tomografia computadorizada, impossibilidade ou dificuldade para punção lombar) ou por questões inerentes ao próprio diagnóstico das condições associadas (e.g. baixa sensibilidade de exames parasitológicos para isospora e criptosporidium, baixa sensibilidade do BAAR para Mycobacterium tuberculosis). Assim, a análise de tendência fundamentada nos dados de notificação pode referir-se, na verdade, às condições associadas presuntivas ocorridas até o momento da notifi cação.

O último ponto quanto à confiabilidade das informações a respeito das condições associadas diz respeito ao fato de não se conseguir captar sua dinâmica de tendência após a notificação, um evento pontual. Esta é limitação importante, em particular, quando se deseja avaliar impacto de tratamentos. Questões como estadiamento clínico na primeira consulta, o acesso às profilaxias primárias (e.g. sulfametoxazol-trimetoprima para PCP e isoniazida para tuberculose) e às secundárias (e.g. fluconazol para criptococose e sulfadiazina para neurotoxoplasmose), o acesso e obtenção dos anti-retrovirais, a aderência mínima recomendada para os mesmos, dentre outros fatores, vão diretamente interferir na ocorrência de novas condições associadas, ou recidivas, ao longo do tratamento destes pacientes. Portanto, a captação da dinâmica temporal das condições associadas não seria completa sem análise da ocorrência das mesmas após a notificação. Tanto a confiabilidade das informações quanto a meIhor caracterização das condições notificadas e a verificação da ocorrência destas, subseqüente à notificação, deveriam ser incorporadas na forma de estudos específicos, provavelmente por amostragem.

\section{Tendência}

O estudo apresentado indica tendência de redução na incidência de todas as condições associadas. Isso ocorre de forma global e de acordo com os subgrupos analisados. Explicações definitivas para tais tendências são difíceis, principalmente quando se consideram as limitações produzidas pelos dados secundários, como comentado acima. Algumas hipóteses podem, no entanto, ser levantadas.

A primeira delas é que estas reduções têm lugar em decorrência da introdução de tratamentos anti-retrovirais combinados e potentes. Diversos estudos vêm demonstrando a redução na mortalidade de indivíduos infectados pelo HIV e que progrediram para AIDS, inclusive no Brasil (Mocroft et al., 1998; Palella et al., 
1998; CNDST/AIDS, 1998a, 1999; Chiasson et al., 1999). Outros estudos também indicam associação entre menor tempo de sobrevida e condições marcadoras de progressão mais graves (e.g. neurotoxoplasmose) e maior risco de morte entre indivíduos que não faziam uso de medicação anti-retroviral (ou utilizavam monoterapia) do que naqueles com terapia dupla ou tríplice com inibidor de protease (Hogg et al., 1999). Há indicações de que o tratamento anti-retroviral combinado possa também alterar a história natural das condições associadas (CDC, 1998; Jacobson \& French, 1998). É possível, portanto, que a redução na incidência das condições associadas esteja de fato associada aos tratamentos anti-retrovirais, já que este recupera, ao menos parcialmente, as condições imunológicas do indivíduo (aumento de linfócitos T CD4+) em virtude, principalmente, do controle virológico (redução da carga viral a níveis indetectáveis ou muito baixos).

Os dados apresentados corroboram essa tendência, principalmente a partir de 1995-96, quando os inibidores de protease começaram a ser disponibilizados na rede pública. Estudos em outros países também indicam reduções importantes na incidência de várias condições associadas. No entanto, a maioria desses estudos é constituída de coortes de indivíduos infectados pelo HIV em acompanhamento (Dore et al., 1997; Buchbinder et al., 1999; Rabkin et al., 1999). Isto permite não só estimativas de risco mais precisas (e.g. incidência pessoastempo), como também avaliação das condições após o evento marcador de progressão para AIDS, procurando determinar associações com o uso de anti-retrovirais. Apesar de não ter sido possível, nessa análise, nenhuma destas duas avaliações, é plausível que a hipótese de redução na incidência destas condições esteja associada com o uso de terapia combinada. Estudos específicos devem ser desenvolvidos para melhor compreensão do impacto da terapia anti-retroviral em condições associadas no Brasil.

Além dos tratamentos anti-retrovirais, os indivíduos infectados pelo HIV podem estar buscando os serviços mais precocemente (estadiamentos mais assintomáticos, CDC A ou B). Esta entrada precoce permite avaliação clínica inicial direcionada ao conhecimento do perfil de risco para determi nadas condi ções associadas (e.g. contagem de linfócitos T CD4+<200/ $\mathrm{mm}^{3}$, sorologia positiva para toxoplasmose, PPD reativo, histórico de herpes simplex ou zoster). Este perfil possibilita a aplicação das recomendações específicas de profilaxias primárias nos serviços de referência, reduzindo, desta forma, a incidência de algumas condições (CDC, 1999).

Como exemplo cita-se a redução mais significativa na incidência de PCP já a partir de 1991 (Figura 6), aproximadamente dois anos após a recomendação do uso de sulfametoxazol-trimetoprima como profilático para indivíduos com contagens de CD4+abaixo de 200/ $\mathrm{mm}^{3}$ (CDC, 1989). No entanto, o mesmo quadro não se observa para a tuberculose, para a qual também existe profilaxia primária (isoniazida). Apesar de existir igualmente redução em sua incidência, esta só é mais acentuada a partir de 1995-96 (Figura 6). É provável que o impacto da terapia anti-retroviral combinada tenha sido maior do que a profilaxia primária para tuberculose.

Outras explicações para a mudança temporal na incidência das condições associadas incluem um viés introduzido pela modificação dos critérios de notificação ao longo do tempo, tal como um provável atraso na notificação dos casos de AIDS. Chama a atenção a última revisão (CNDST/AIDS, 1998a) que introduziu a notificação para indivíduos com contagem de linfócitos T CD4+abaixo de 350/ $\mathrm{mm}^{3}$. Indivíduos com contagens de linfócitos T CD4+ entre 200 e $350 / \mathrm{mm}^{3}$ ainda se encontram em fase de menor risco para a maioria das condições associadas. Este fato, portanto, poderia estar reduzindo artificialmente a incidência das mesmas por aumento do denominador. No entanto, tal modificação só ocorreu em 1998, não afetando anos anteriores. De qualquer forma, é fato a ser levado em conta em futuras análises. Além disso, a disponibilidade dos resultados da contagem de linfócito T CD4+pode auxiliar na melhor compreensão desta dinâmica temporal.

\section{Escolaridade}

A análise de tendência das condições associadas de acordo com a escolaridade não é diferente do quadro global ou quando comparado com as outras variáveis estudadas (região, sexo, idade e categorias de exposição). A redução ocorre nas quatro categorias (analfabetos, 10 grau, 2o grau+e ignorados), mas não de forma homogênea para todas as condições (Tabela 4). Chama a atenção a maior incidência de tuberculose entre analfabetos e 1o grau para todos os anos - fato que também ocorre entre indivíduos não infectados pelo HIV - e o aumento na $\mathrm{RI}$ entre os períodos inicial e final, apesar da redução na incidência em todas as categorias (Figura 4). Deve-se investigar a hipótese de que benefícios advindos da profilaxia e do trata- 
Figura 6

Incidência (por 100) das condições associadas, por ano, entre casos de AIDS notificados em maiores de 12 anos, Brasil, 1980-1999.

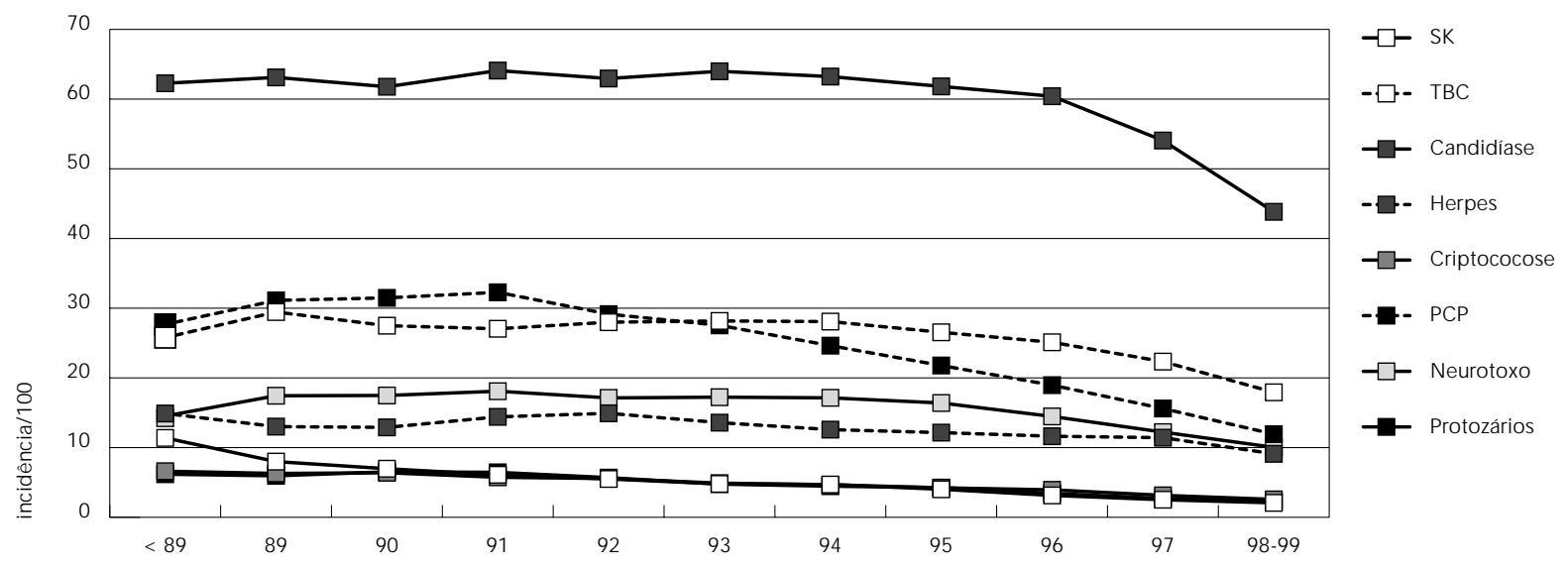

mento anti-retroviral possam ser diferenciais para diferentes subgrupos, incluindo escolaridade e outras variáveis marcadoras de condições sócio-econômicas.

Interessante observar a tendência da incidência de PCP. Verifica-se, a partir de 1990, maior incidência entre aqueles com 20 grau+e redução praticamente paralela àqueles com 10 grau a partir de 1991 (Figura 5). Aparentemente houve benefício comum (e.g. profilaxia primária) às quatro categorias, persistindo maior incidência de PCP entre aqueles com 20 graut, mas que é minimizada ao final do período. A maior incidência nos períodos iniciais pode ter ocorrido em virtude do mai or acesso de indivíduos com melhor escolaridade a procedimentos diagnósticos, da maior percepção de sinais e sintomas que estimulassem estes indivíduos a adquirirem maior poder de enfrentamento na busca e obtenção da atenção à saúde e, por último, da existência de fato de maior incidência neste grupo. Este último ponto poderia ser corroborado pelo fato de a incidência de PCP ter sido maior entre homo/ bissexuais com meIhor poder aquisitivo no início da epidemia. Tal diferencial estaria sendo diluído na medida em que o acesso à profilaxia primária e ao tratamento anti-retroviral se tornou mais disponível no serviço público. É possível que este fenômeno também tenha ocorrido com Sarcoma de Kaposi, cuja maior incidência entre aqueles com melhor escolaridade, no início da epidemia, praticamente desaparece ao final do pe- ríodo, apesar da não existência de profilaxia primária para esta condição. Houve também maior redução na incidência de SK para os homens, os mais velhos(30+anos), e entre os Homo/Bissexuais.

Por último, observa-se também que a distribuição da variável escolaridade entre aqueles com cada condição é bastante semelhante ao total de casos de AIDS em maiores de 12 anos. Para cada condição, há aumento na proporção de indivíduos com 10 grau e analfabetos, e diminuição daqueles com 2 o graut, indicando aumento do peso que se evidencia para aqueles com menor escolaridade no total de casos notificados a cada ano. Percentuais semelhantes de informação ignorada para escolaridade também levantam a hipótese de meIhoria na qualidade da informação e a limitação que este dado apresenta no estudo temporal das condições associadas.

\section{Conclusões}

Considerando, portanto, as limitações expostas acima, algumas conclusões com relação à tendência temporal das condições associadas podem ser feitas: a) há tendência de redução na incidência de todas as condições estudadas, em especial, a partir de 1995-96; b) essa tendência é comum a todas as análises por subgrupo das variáveis estudadas, com al gum grau de heterogeneidade que merece ser aprofun- 
dada; c) a distribuição das condições associadas por escolaridade segue a mesma tendência dos casos de AIDS notificados entre indivíduos maiores de 12 anos de idade, i.e., aumento da proporção de indivíduos com escolaridade 10 grau e diminuição daqueles com 2 o grau + ; d) a tendência de redução na incidência das condições associadas se confirma também para as categorias de escolaridade, apesar de diferenças na magnitude desta redução para algumas das condições. No entanto, quando se compara a incidência no período inicial e final, constata-se tendência de aumento no risco para analfabetos e 1o grau, quando comparados com aqueles com 2o graut, para a maioria das condições. São necessárias mais investigações para se aprofundar prováveis hipóteses causais; e) é provável que a redução na inci dência ocorra principalmente em decorrência do uso de profilaxias primárias e/ ou tratamentos antiretrovirais, hipóteses que precisam igualmente ser melhor exploradas; f) é necessário que se desenvolvam estudos de confiabilidade para melhor avaliação das categorias de informação ignorada (e.g. escolaridade, categorias de exposição), além da padronização dos critérios de notificação das condições associadas; g) a abordagem das condições associadas não deve se ater ao momento da notificação, devendo ser desenvolvidos estudos específicos que verifiquem as tendências também após este fato pontual; h) apesar da tendência de redução na incidência de todas as condições de forma global, alguns subgrupos apresentaram inclinações negativas pequenas ou até mesmo aumento (e.g. tuberculose na região Nordeste), o que é motivo de preocupação e merece, da mesma forma, ser investigado.

\section{Referências}

BRODT, H. R.; KAMPS, B. S.; GUTE, P.; KNUPP, B.; STASZEWSKI, S. \& HELM, E. B., 1997. Changing incidence of AIDS-defining illnesses in the era of antiretroviral combination therapy. AIDS, 11:17311738.

BUCHBINDER, S. P.; HOLMBERG, S. D.; SCHEER, S.; COLFAX, G.; O'MALLEY, P. \& VITTINGHOFF, E., 1999. Combination antiretroviral therapy and incidence of AIDS-related malignancies. Journal of Acquired Immune Deficiency Syndrome, 21:S23S26.

CDC (Centers for Disease Control and Prevention), 1989. Guidelines for prophylaxis against Pneumocystis carinii pneumonia for persons infected with human immunodeficiency virus. MMWR, 38(Sup. 5):1-9.

CDC (Centers for Disease Control and Prevention), 1992. Revised classification system for HIV infection and expanded surveillance case definition for AIDS among adolescent and adults. MMWR, 41(RR-17):1-19.
CDC (Centers for Disease Control and Prevention), 1998. Report of the NIH panel do define principles of therapy of HIV infection and guidelines for for use of antiretroviral agents in HIV-infected adults and adolescents. MMWR, 47(RR5):1-41.

CDC (Centers for Disease Control and Prevention), 1999. USPHS/IDSA Guidelines for the prevention of Opportunistic Infections in persons infected with human immunodeficiency virus. MMWR, 48(RR-10):1-67.

CHIASSON, M. A.; BERENSON, L.; LI, W.; SCHWARTZ, S.; SINGH, T.; FORLENZA, S.; MOJICA, B. A. \& HAMBURG, M. A., 1999. Declining HIV/AIDS mortality in New York City. Journal of Acquired Immune Deficiency Syndromes and Human Retrovirology, 21:59-64.

CNDST/AIDS (Coordenação Nacional de DST e AIDS), 1992. Revisão da Definição Nacional de AIDS em Adultos. Brasília: Divisão de DST/AIDS, Ministério da Saúde. 
CNDST/ AIDS (Coordenação Nacional de DST e AIDS), 1998a. Revisão da Definição Nacional deAIDS em Indivíduos com 13 Anos ou Mais. Brasília: Divisão de DST/AIDS, Ministério da Saúde.

CNDST/ AIDS (Coordenação Nacional de DST e AIDS), 1999. Boletim Epidemiológico - AIDS, XII(1).

DORE, G. J.; HOY, J. F.; MALLAL, S. A.; LI, Y.; MIJCH, A. M.; FRENCH, M. A.; COOPER, D. A. \& KALDOR, J. M., 1997. Trends in incidence of AIDS illnesses in Australia from 1983 to 1994: The Australian AIDS Cohort. Journal of Acquired Immune Deficiency Syndromeand Human Retrovirology, 16:39-43.

HOGG, R. S.; YIP, B.; KULLY, C.; CRAIB, K. J. P.; O'SHAU GHNESSY, M. V.; SCHECHTER, M.T. \& MONTANER, J. S. G., 1999. Improved survival among HIV-infected patients after initiation of triple-drug antiretroviral regimens. Canadian Medical Association Journal, 160:659-665.

JACOBSON, M. A. \& FRENCH, M., 1998. Altered natural history of AIDS-related opportunistic infections in the era of potent combination antiretroviral therapy. AIDS, 12(Sup. A):S157-S163.

JACOBSON, L. P.; YAMASHITA, T. E.; DETELS, R.; MARGOLICK, J. B.; CHMIEL, J. S.; KINGSLEY, L. A.; MELNICK, S. \& MUÑOZ, A., 1999. Impact of potent antiretroviral therapy on the incidence of Kaposi's Sarcoma and Non-Hodgkin's Lymphomas among HIV-1 infected individuals. Journal of Acquired Immune Deficiency Syndrome, 21:S34-S41.

MOCROFT, T. A.; VELLA, S.; BENFIELD, T. L.; CHIESI, A.; MILLER, V.; GARGALIANOS, P.; MONFORTE, D. A.; YUST, I.; BRUUN, J. N.; PHILLIPS, A. N. \& LUNDGREN, J. D., 1998. Changing patterns of mortality accross Europe in patients infected with HIV-1. Lancet, 352:1725-1730.

PALELLA Jr., F. J.; DELANEY, K. M.; MOORM AN, A. C.; LOVELESS, M. O.; FUHRER, J.; SATTEN, G. A.; ASCHMAN, D. J.; HOLMBERG, S. D. \& THE HIV OUTPATIENT STUDY INVESTIGATIONS, 1998. Declining morbidity and mortality among patients with advanced human immunodeficiency virus infection. HIV Outpatient Study Investigators. New England Journal of Medicine, 338:853860.

RABKIN, C. S.; TESTA, M. A.; HUANG, J. \& VON ROENM, J. H., 1999. Kaposi's Sarcoma and NonHodgkin's Lymphoma incidence trends in AIDS Clinical Trial Group Study participants. Journal of Acquired Immune Deficiency Syndrome, 21:S31S33. 